Board of Governors of the Federal Reserve System

International Finance Discussion Papers

Number 613

June 1998

\title{
MACROECONOMIC IMPLICATIONS OF COMPETITIVE COLLEGE ADMISSIONS
}

\author{
Murat F. Iyigun and Andrew T. Levin
}

NOTE: International Finance Discussion Papers are preliminary materials circulated to stimulate discussion and critical comment. References in publications to International Finance Discussion Papers (other than an acknowledgment that the writer has had acccess to unpublished material) should be cleared with the author or authors. Recent IFDPs are available on the Web at www.bog.frb.fed.us. 


\title{
MACROECONOMIC IMPLICATIONS OF COMPETITIVE COLLEGE ADMISSIONS
}

\author{
Murat F. Iyigun and Andrew T. Levin*
}

\begin{abstract}
We present a public higher education model in which there exist indivisibilities in educational investment. Consequently, when demand for educational services exceed supply, a screening mechanism, which may potentially be imperfect, is required to choose the student body. We demonstrate how distortions or biases in screening-caused by parental factors-interact with the distribution of income to help explain the considerable differences across countries in the share of resources devoted to public higher education. Moderate degrees of admission bias lower the equilibirum share of resources devoted to public education whereas higher levels of bias may have positive effects on public education supply. Thus, while lower screening biases lead to a better allocation of a given amount of spending on education, they do not necessarily lead to more political support for public higher education, and thereby to higher aggregate human capital and output. When wage rates are endogenous, the effects of screening biases on public higher education supply can be positive even for smaller biases. Moreover, higher inequality will lead to a lower share of resources devoted to public higher education when biases are relatively moderate.
\end{abstract}

keywords: Public Education, Income Distribution, Screening.

* The authors are economists in the Division of International Finance, Board of Governors of the Federal Reserve System. The views in this paper are solely the responsibility of the authors and should not be interpreted as reflecting the views of the Board of Governors of the Federal Reserve System or of any other person associated with the Federal Reserve System. Please send all correspondence to: The Board of Governors of the Federal Reserve System, Mail Stop 23, Washington, D.C. 20551. 


\section{Introduction}

Education, at all levels and in all countries, is a special good for which prices do not solely determine allocation. In fact, in a majority of industrialized and developing countries, education is a publicly provided good which is allocated via exams and tests that are intended to measure individuals' true productive abilities. There are a number of justifications for relying on tests as a screening device for the provision of education. One of the most apparent is that, in the presence of capital market imperfections and positive aggregate production externalities, relying on tests as an allocation mechanism helps achieve more efficient outcomes. ${ }^{1}$

Moreover, cross-country studies of education finance reveal that, even at the tertiary level, there is considerable variation in the share of resources devoted to public education finance. In some countries like the United States where private education is relatively common, public policy is still very relevant for long-run economic performance, educational attainment and the design of associated redistributive mechanisms. The specific nature of this relationship has been the focus of a number of theoretical studies, most of which predict income inequality to be positively correlated with redistribution and negatively with long-run economic growth. ${ }^{2}$ These studies also imply a transfer of resources from high to low income individuals because inequality raises the social propensity to redistribute income. While empirical studies have supported a robust negative relationship between income inequality and subsequent long-run economic performance, ${ }^{3}$ they do not support the hypothesis that higher inequality raises the social propensity to redistribute resources from the rich to the poor. ${ }^{4}$ In fact, a number of empirical studies have documented that higher public education involves implicit transfers in the reverse direction. $^{5}$

\footnotetext{
${ }^{1}$ See, for example, Fernandez(1998) and Fernandez and Gali(1997).

${ }^{2}$ A recent exception is Benabou (1996) which demonstrates how societies with identical technologies and preferences and similar democratic systems can devote a significantly differing share of their total resources to redistribution.

${ }^{3}$ See, for example, Persson and Tabellini (1994), Alesina and Rodrik (1994) and Perotti (1996).

${ }^{4}$ See, for example, Perotti $(1994,1996)$.

${ }^{5}$ A non-exhaustive list of such empirical work would include Radner and Miller (1970), Peltzman (1973) and Psacharopoulos (1986). Fernandez and Rogerson (1995) discuss these as well as others to motivate a model of partial education subsidies that generate transfers consistent with empirical findings. They demonstrate that in economies in which the poor are excluded from obtaining education, their tax
} 
At the same time, there exists a long and on-going debate on inherent biases or distortions in screening for higher education admissions. For example, in the United States, it is often argued that college-prep courses merely enhance SAT performance by providing useful test-taking strategies and that these courses do not augment human capital in any other way. Similarly, "private guidance counselors" help high school seniors improve their admission odds by supporting them in strenghtening other aspects of their applications. As these examples suggest, it is often argued that screening biases in some cases are related to socio-economic advantages high income households provide to their young. Some of these advantages may be available to individuals from wealthy households even without expending any resources. For example, more educated parentswho, in general, also tend to be relatively more wealthy-can provide better support and guidance to their offspring in college admissions. Regardless of their source though, it is well-documented that screening biases lead to lower intergenerational economic mobility ${ }^{6}$ and-given that they exclude relatively able individuals who come from disadvantaged households from receiving education-to aggregate inefficiencies. Then, a natural question to ask is how some of these inherent testing biases may affect public choice with respect to how large and what quality a public education system to sustain. In particular, while the use of tests in screening for access to higher public education can be justified for reasons of allocative efficiency, it is possible that inherent biases in tests adversely affect political support for public higher education, thereby leading to lower aggregate human capital and output.

To the best of our knowledge, there is little-if any-in the existing literature on the role of biased admissions in the political economy of public education finance, and we carry out that exploration here. In what follows, we focus on distortions in screeningbiases in access to education caused by family characteristics irrelevant to individuals' productive capabilities-as an important factor in the political economy of public education finance. We present a model of public higher education where, due to indivisibilities payments in effect subsidize those who are relatively more wealthy and who demand more educational services.

${ }^{6}$ See, for example, Iyigun(forthcoming). 
in educational investment, ${ }^{7}$ admission to public schools are competitive when demand for educational services exceeds its supply.

Our model yields several important conclusions. First, it shows that while a less biased screening test leads to higher allocative efficiency, it does not necessarily lead to higher output. The reason is that a voter who does not benefit from biases will choose to allocate a larger fraction of resources to public education when biases are relatively high. Put differently, the exclusion effect of screening distortions are strongest when screening distortions are relatively small. In fact, we show below that biases have three potentially offsetting effects on the share of resources that voters would prefer to allocate to public education. First, they shift the relative position of influential voters' children in the competition to qualify for admission to schools. When biases are relatively large, other voters benefit from this shift because their offspring's odds of entry to a public school at the margin rises. In contrast, when biases are rather moderate, they lose from such a shift because biases in that case mean more competition from the children of influential parents who benefit from screening distortions. Second, when there are biases, more resources need to be devoted to public education supply as a higher fraction of individuals qualify for admission to schools. For fixed wage rates, whether the net effect of greater biases in screening on equilibrium tax rates is negative or positive depends on whether biases are large enough to lead to improved odds for gaining admissions for the children of decisive voters. When wage rates are endogenous and there exists complementarities between educated and uneducated labor in production, screening biases affect the macroeconomy and the share of resources devoted to public education through a third channel: Because biases lead to inefficiencies in higher education admissions (by allocating the scarce slots to relatively less able students from influential households), they artificially inflate the skill premium-the difference between educated and uneducated workers' wage rates. Our model shows that the impact of this last effect on resources devoted to public higher education is unambigiously positive.

Second, the model presented below demonstrates that the extent to which screening distortions effectively exclude voters from the use of public education not only influences

\footnotetext{
${ }^{7}$ This approach is similar in spirit to the one first proposed by Galor and Zeira (1993).
} 
the share of resources devoted to the supply of public education but also the relationship between inequality and the support for public education. It shows that higher inequality will lead to a smaller share of resources to be devoted to public higher education when biases are relatively moderate. Consequently, the model provides a potential explanation as to why higher inequality is not associated with more redistributive policies. It shows that when the proxy for measuring abilities is moderately influenced by parental characteristics, higher inequality may reduce the decisive voter's influence in admissions and therefore his propensity to support higher redistribution. Thus, the negative relationship between income inequality and redistribution holds. Nonetheless, our model also indicates that when screening biases are large, higher inequality may lead to a larger transfer of resources from the rich to the poor because higher inequality-at the margin-raises the odds of getting educated for less influential individuals.

Finally, the extent to which screening for admission to public schools are biased by family characteristics determines what fraction of the population is effectively excluded from getting educated. Coupled with the fact that higher screening biases lead to a larger share of the population being effectively excluded from getting educated, a public system financed by a proportional income tax can be supported even by a restricted franchise. The reason is that with proportional income taxation and a sufficiently large fraction of the population being effectively excluded from getting into schools, the cost of public education may be lower than that of private education. While our model is not the first to generate such an empirically consistent result ${ }^{8}$ it stresses the potential role of biased screening in leading to transfers from the poor to the rich.

The remainder of our paper is organized as follows. Section 2 lays out the basic analytical framework. Section 3 describes the admissions process and discusses the potential outcome of voting. Section 4 examines how screening biases interact with income inequality to determine the share of resources devoted to public education. Section 5 endogenizes the skill premium and explores the impact of screening biases on efficiency in aggregate production, on the skill premium, and on the voters' choices. Section 6 discusses the relevant literature, and section 7 concludes.

\footnotetext{
${ }^{8}$ See, for example, Fernandez and Rogerson (1995).
} 


\section{The Model}

Consider an economy in which there is a single consumption good and a continuum of parents of measure one. Parents, who live for two periods, get utility-without discounting-from their own consumption and from the expected consumption of their offspring. There is no population growth and each parent has one offspring.

In the first period of life, parents consume and vote on the share of resources to be devoted to public higher education in the following period. In the second period, they send their offspring to a public school if they are admitted. There is no borrowing. We assume that parent $i$ 's utility from her own consumption in period one and from her offspring's consumption in period two has a log-linear form:

$$
u_{i}=\lambda \ln \left(c_{i, 1}\right)+(1-\lambda) E\left[\ln \left(c_{i, 2}\right)\right]
$$

where $0<\lambda<1$, and where $c_{i, 1}$ and $c_{i, 2}$ respectively denote parent $i$ 's consumption in period one and the consumption of $i$ 's offspring in period two.

The ability endowments of the offspring are log-normally distributed, with $a_{i} \equiv$ $\log A_{i} \sim N(0,1)$. Given that the higher education system is public and that parents do not know their offspring's abilities when voting on the preferred share of resources to be devoted to education, the following constraints apply to maximizing (1):

$$
\begin{gathered}
c_{i, 1} \leq\left(1-\tau_{i}^{*}\right) y_{i}, \\
E\left[\ln \left(c_{i, 2}\right)\right]=\Phi\left(a_{i}^{*}\right) \ln \left(w^{u}\right)+\left[1-\Phi\left(a_{i}^{*}\right)\right] \ln \left(w^{e}\right),
\end{gathered}
$$

where $\phi($.$) and \Phi($.$) respectively denote the probability density function (p.d.f.) and$ the cumulative distribution function (c.d.f.) of the log of innate abilities, and where $w^{e}$ and $w^{u}, w^{e}>w^{u}$, respectively represent wage rates paid to educated and uneducated offspring. In $(2), \tau_{i}^{*}$ represents individual $i$ 's preferred tax rate and $a_{i}^{*}$ the log of the minimum ability level of $i$ 's offspring required for admission to a public school. 


\section{Admissions and Optimal Tax Rates}

Let $c, c>0$, denote the cost of education per pupil, and $y$ denote aggregate wealth in period one. Then, the supply of educational services in the second period, $S$, will be given by

$$
S=\frac{\tau^{*} y}{c}
$$

where $\tau^{*}$ represents the equilibrium tax rate.

We assume that when the supply of public education, $S$, is less than its demand ${ }^{9}$, applicants are admitted to schools based on their measurable productive abilities. ${ }^{10}$ To make the problem interesting, however, we also assume that the proxy for measuring individuals' productive abilities is imperfect. In particular, we consider the proxy to be potentially influenced by the characteristics of parents. ${ }^{11}$ Let $I_{i}, I_{i}: R^{2} \rightarrow R$, denote the $\log$ of the ability of parent $i$ 's offspring as measured with the available proxy. Then,

$$
I^{i}= \begin{cases}a_{i}+\beta & \text { with probability } p \\ a_{i} & \text { with probability } 1-p\end{cases}
$$

where $\beta \geq 0$. As (4) indicates, we assume that $p$ fraction of parents positively bias their offspring's measured abilities, whereas $1-p$ fraction have no influence on the measured ability levels of their offspring. ${ }^{12}$

If the measured ability level of parent $i$ 's offspring is greater than or equal to the threshold level, $I^{*}$, then $i$ is admitted to a public school and she earns $a_{i} w^{e}$ in the second

\footnotetext{
${ }^{9}$ Note that, in our simple framework, the demand for education equals one as the second period wage earnings of educated labor is higher than that of uneducated labor for all ability levels.

${ }^{10}$ For sake of simplicity, we abstract from any cost associated with screening.

${ }^{11}$ Although we do not specify which parental characteristics are important in generating favorable biases in screening for higher education admissions, as we have noted in the introduction, most of these are socio-economic in nature. There are also on-going debates on whether standardized tests favor members of certain gender, race or ethnicity.

${ }^{12}$ In our view, a more comprehensive version of (4) ought to include a measurement error term. Although, for simplicity, we abstract from it in the version provided here, we show in the appendix that the qualitative nature of our results are robust to such a modification.
} 
period. Otherwise, she remains uneducated and earns $a_{i} w^{u}$. Let $a_{p}^{*}$ and $a_{1-p}^{*}$ respectively denote the relevant thresholds of admission for influential and non-influential parents' offspring. Equation (4) implies that the threshold ability necessary to gain admission for children who belong to influential parents is less than or equal to that of offspring who belong to non-influential parents. That is, $a_{p}^{*}=I^{*}-\beta \leq a_{1-p}^{*}=I^{*}$. Note that $I^{*}$ satisfies the following:

$$
S=1-\Psi\left(I^{*}\right)
$$

where $\Psi\left(I^{*}\right)$ denotes the population c.d.f.

In deciding on the optimal share of resources devoted to higher public education, parents maximize (1) subject to (2)-(5). It is straightforward to show that parent $i$ prefers a tax rate, $\tau_{i}^{*}$, which satisifies the following first-order condition:

$$
\frac{\partial u_{i}}{\partial I^{*}}=-\frac{\lambda}{1-\tau^{*}} \frac{\partial \tau^{*}}{\partial I^{*}}-(1-\lambda) \ln \left(\frac{w^{e}}{w^{u}}\right) \phi\left(a_{i}^{*}\right) \leq 0,
$$

where

$$
\frac{\partial \tau^{*}}{\partial I^{*}}=-\frac{c}{y} \psi\left(I^{*}\right)=-\frac{c}{y}\left[p \phi\left(I^{*}-\beta\right)+(1-p) \phi\left(I^{*}\right)\right] .
$$

The first term in (6) denotes the marginal cost in terms of utility of lowering the admissions threshold and the second term represents its marginal benefit. Note that, while the benefit of raising the supply of higher public education depends positively on the p.d.f. of the ability of parent $i$ 's offspring at that threshold, $\phi\left(a_{i}^{*}\right)$, the cost of raising supply is related to the p.d.f. of abilities for the whole population. In (7), that latter term is given by the mixture density function $\psi\left(I^{*}\right), \psi\left(I^{*}\right)=p \phi\left(I^{*}-\beta\right)+(1-p) \phi\left(I^{*}\right)$. Put differently, the net marginal benefit of lowering the admissions threshold, $I^{*}$, depends positively on the probability density of the ability of parent $i$ 's offspring relative to that of the population at that threshold. When the ratio of the voter's offspring density to 
population density is small, the net marginal benefit is low as most of the benefits of lowering the admissions threshold accrue to the children of other groups.

Figure 1 shows, for $\beta=3$, the log-ability densities for the children of non-influential and influential parents, $\phi($.$) , as well as the mixture p.d.f. for the whole population, \psi($.$) .$ Note how, at relatively high cutoff levels of the threshold indicator, $I_{i}$, the mixture density function, $\psi($.$) , lies above the density function of log-abilities for the offspring$ of non-influential parents. In contrast, at lower threshold levels, the density of logabilities for offspring of those parents exceeds that of the population. The associated marginal utility and disutility of taxes are depicted in Figure 2. As is consistent with the above analysis, the net marginal utility of resources devoted to public education for non-influential parents becomes positive (and their utility peaks) only at relatively lower threshold levels.

[Figures 1 and 2 about here.]

Note that in the limiting case where $\beta \rightarrow 0$, the ratio of the densities approach one, and an interior solution to the maximization problem exists if $\frac{1-\lambda}{\lambda} \ln \left(\frac{w^{e}}{w^{u}}\right)>\frac{y}{c}>$ $\frac{\frac{1-\lambda}{\lambda} \ln \left(\frac{w^{e}}{w^{u}}\right)}{1+\frac{1-\lambda}{\lambda} \ln \left(\frac{w^{e}}{w^{u}}\right)}$. In that case neither screening biases, $\beta$, nor the fraction of influential parents, $p$, has an influence on the equilibrium share of resources devoted to public education supply.

The analysis changes markedly, however, when $\beta>0$. To see this, let $d, 0 \leq d \leq 1$, denote the critical fraction of votes required for a given tax rate to be chosen through the political system. ${ }^{13}$ For the remainder of the analysis, we assume that $p<d$ so that the decisive voter is a non-influential parent. In that case, the equilibrium tax rate satisfies

$$
\frac{\partial u_{L}}{\partial I^{*}}=-\frac{\lambda}{1-\tau^{*}} \frac{\partial \tau^{*}}{\partial I^{*}}-(1-\lambda) \ln \left(\frac{w^{e}}{w^{u}}\right) \phi\left(I^{*}\right) \leq 0
$$

and,

\footnotetext{
${ }^{13}$ With this formulation, we allow individual preferences to be aggregated not only through the median voter framework (i.e. $d=\frac{1}{2}$ ) but also by variants of it in which some agents may have more weight in the political process than others (ie. $d \neq \frac{1}{2}$ ).
} 


$$
\frac{\partial^{2} u_{L}}{\partial\left(I^{*}\right)^{2}}<0
$$

with $\frac{\partial \tau^{*}}{\partial I^{*}}$ given by $(7)$. [We show in the appendix that there exists one interior solution tax rate, $\tau^{*}>0$, that satisfies equations (8) and (9).]

First, note that, when non-influential parents are the decisive voters and the equilibrium tax rates are determined by them, the share of resources devoted to public education supply is lower when there are biases in screening only if $\phi\left(I^{*}-\beta\right)>\phi\left(I^{*}\right)$. This can be the case when $I^{*}>\beta$. Put differently, when parameter values are such that competition amond applicants are high and a relatively small fraction of applicants could be admitted to public schools (i.e. $I^{*}$ is relatively high), moderate biases lower the odds of entry to a public school of children born to non-influential parents. Consequently, non-influential parents would choose to devote less resources to the supply of public education.

More formally, let $G=\frac{\partial u_{L}}{\partial I^{*}}=0$. Using the implicit function theorem it is straightforward to show that

$$
\frac{\partial \tau^{*}}{\partial \beta}=-\frac{G_{\beta}}{G_{\tau^{*}}}=\frac{p \phi\left(I^{*}-\beta\right)}{G_{\tau^{*}}} \frac{\lambda}{1-\tau^{*}} \frac{c}{y}\left[2\left(I^{*}-\beta\right)+\frac{1}{1-\tau^{*}} \frac{c}{y} \psi\left(I^{*}\right)\right] .
$$

By assumption, $\tau^{*}$ is an interior solution to the maximization problem of a noninfluential parent, and as a result, $G_{\tau^{*}}$ is strictly negative. The term in brackets show the two potentially offsetting effects of higher biases in screening: $2\left(I^{*}-\beta\right)$ represents how, at the threshold $I^{*}$, a given supply of educational services benefit or harm less influential voters. This effect arises because screening biases shift the relative position of influential parents' offspring in the $I_{i}$ map. When $I^{*}<\beta$, non-influential voters benefit from this shift because their offspring's odds of entry to a public school at the margin rises. In contrast, when $I^{*}>\beta$, they lose from such a shift because higher biases in that case means more competition from influential parents' offspring at the margin. The 
second term in brackets in equation (10), $\frac{1}{1-\tau^{*}} \frac{c}{y} \psi\left(I^{*}\right)$, represents the effect on utility of a higher fraction of children born to influential parents qualifying for admission at a given threshold, $I^{*}$. This effect arises because when biases are larger, more resources need to be devoted to public education supply as a higher fraction of influential parents' offspring qualify for admission to schools. Clearly, this effect is always negative. In sum, whether the net effect of greater biases in screening on equilibrium tax rates is negative or positive depends on whether biases are large enough to lead to improved odds for gaining admissions for the decisive voters' offspring-that is, non-influential parents' children. Figure 3 demonstrates how, for a positive threshold cutoff level, $I^{*}$, a relatively low (high) degree of parental influence, $\beta$, raises (lowers) the population density above (below) that of the density of indicators for the offspring of non-influential parents.

[Figure 3 about here.]

Note that (10) also implies that the effect of screening biases, $\beta$, on the equilibirum share of resources devoted to public education, $\tau^{*}$, approaches zero as biases approach infinity. Namely

$$
\lim _{\beta \rightarrow \infty}\left(\frac{\partial \tau^{*}}{\partial \beta}\right)=0
$$

\section{Screening Biases and Income Inequality}

The other relevant comparative-static analysis is to examine what-if any-effect changes in inequality have on the equilibrium share of resources devoted to public education supply. ${ }^{14}$ Invoking the implicit function theorem once again, we derive

$$
\frac{\partial \tau^{*}}{\partial p}=-\frac{G_{p}}{G_{\tau^{*}}}=-\frac{1}{G_{\tau^{*}}} \frac{\lambda}{1-\tau^{*}} \frac{c}{y}\left\{\begin{array}{c}
\phi\left(I^{*}\right)-\phi\left(I^{*}-\beta\right)+ \\
\frac{1}{1-\tau^{*}} \frac{c}{y} \psi\left(I^{*}\right)\left[\Phi\left(I^{*}-\beta\right)-\Phi\left(I^{*}\right)\right]
\end{array}\right\}
$$

\footnotetext{
${ }^{14}$ For the purposes of examining this section, we assume that screening biases are directly related to parental socio-economic factors, such as wealth, income or social status.
} 
And using (12) we can show

$$
\lim _{\beta \rightarrow 0}\left(\frac{\partial \tau^{*}}{\partial p}\right)=0
$$

and,

$$
\lim _{\beta \rightarrow \infty}\left(\frac{\partial \tau^{*}}{\partial p}\right)=-\frac{\phi\left(I^{*}\right)}{G_{\tau^{*}}} \frac{\lambda}{1-\tau^{*}} \frac{c}{y}\left\{1-\frac{1}{1-\tau^{*}} \frac{c}{y} \Phi\left(I^{*}\right)\right\}
$$

In equation (12), the term $\phi\left(I^{*}\right)-\phi\left(I^{*}-\beta\right)=\frac{\partial \psi\left(I^{*}\right)}{\partial p}$ represents how an increase in the fraction of influential parents change population density at the threshold ability indicator, $I^{*}$. That effect is negative when $I^{*}>\beta$ and it can be positive when $I^{*}<\beta$. That is because when $I^{*}>\beta\left(I^{*}<\beta\right)$, a rise(fall) in the population density at $I^{*}$, lowers(raises) the odds of admission and raises(lowers) marginal cost at the threshold ability indicator, $I^{*}$. The second term in $(12), \frac{1}{1-\tau^{*}} \frac{c}{y} \psi\left(I^{*}\right)\left[\Phi\left(I^{*}-\beta\right)-\Phi\left(I^{*}\right)\right]$, shows the effect on utility of a higher fraction of influential parents' offspring qualifying for admission at a given threshold, $I^{*}$. As was the case in the analysis of equation (10), this effect arises because when the fraction of influential parents is higher, more resources need to be devoted to public education supply as more individuals qualify for admission to schools. Therefore, the effect on utility of this term is always negative when $\beta>0$.

Considering both effects and taking into account (13), the effect on the equilibrium tax rate, $\tau^{*}$, of an increase in the fraction of influential parents, $p$, is strictly negative when $I^{*}>\beta>0$. Nonetheless, (14) also indicates that for larger biases in screening (when $I^{*}<\beta$ ), it is possible that an increase in the fraction of influential parents improve sufficiently the odds of gaining admission to a public school for the children of less influential parents that it offsets the negative effects on utility of more resources being spent on public education. Then, greater inequality will lead to a higher equilibrium tax rate, $\tau^{*}$, and an increase in the supply of public higher education.

Figures 4 and 5 show how changes in the fraction influential parents affect the net marginal benefit of public education to non-influential voters. In Figure 4 where $\beta=1$, an increase in the fraction of parents with influence in screening, $p$, leads to a lower 
ratio of own density to population density, and hence, to lower net marginal benefit to non-influential voters. In contrast, in Figure 5 where $\beta=3$, an increase in the fraction of parents with influence, $p$, leads to a higher ratio of own density to population density, and hence, to higher net marginal benefit.

[Figures 4 and 5 about here.]

So far we have only considered how the preferred tax rate of non-influential parents is affected by changes in screening biases and inequality. Nonetheless, it is also worthwhile-as it will become apparent shortly-to examine how influential parents' choices compare with others. Using (6), we can show that the tax rate that wealthy individuals prefer satisfies the first-order condition

$$
\frac{\partial u_{H}}{\partial I^{*}}=-\frac{\lambda}{1-\tau^{*}} \frac{\partial \tau^{*}}{\partial I^{*}}-(1-\lambda) \ln \left(\frac{w^{e}}{w^{u}}\right) \phi\left(I^{*}-\beta\right)=0,
$$

with $\frac{\partial \tau^{*}}{\partial I^{*}}$ still given by (7). As a comparison of the terms $\phi\left(I^{*}-\beta\right)$ in $(15)$ and $\phi\left(I^{*}\right)$ in (8) indicates, whether influential parents support a higher or a lower tax rate than that preferred by non-influential voters depends critically on whether biases are large. In particular, the higher the biases, the lower is the tax rate and the higher the cutoff threshold proxy, $I^{*}$ that satisfies $(15)$. The reason for this is fairly straightforward: When biases are large, admission to a public school of influential parents' offspring is virtually guaranteed, and such parents do not support higher tax rates for which almost all benefits accrue to the children of others. A direct consequence of the preceding analysis is that, influential individuals may prefer a public education system over a private one when biases are sufficiently large. That is simply because the inherent admission uncertainty which makes a public education system less desirable is effectively eliminated for influential individuals when biases are large. Moreover, with proportional income taxation and a sufficiently large fraction of the population being effectively excluded from getting into schools, the cost of public education becomes lower than that of private education 
for influential parents' offspring.

\section{Endogenous Wage Differentials}

In this section we demonstrate how the positive effect of screening biases on public education supply is reinforced when the wage rates are endogenous. The main difference of the following anaysis from the one above is that, when wages paid to educated and uneducated workers are endogenously determined, screening distortions affect not only how much of the total resources voters prefer to allocate to the provision of public higher education but also how-through the misallocation effect-biases inflate the skill premium.

More formally, let the second period aggregate output, $y_{2}$, be given by a CES production function:

$$
y_{2}=\left[B E^{\rho}+(1-B) U^{\rho}\right]^{\frac{1}{\rho}}, \quad B>0,
$$

where $E$ and $U$ respectively denote the efficiency units of educated and uneducated labor input, and where $\rho,-\infty \leq \rho \leq 1$, denotes the elasticity of substitution. Using the notation in the preceding sections, the efficiency units of educated and uneducated labor input will be given by the following:

$$
E=p_{I^{*}-\beta} \int^{\infty} \exp (a) \phi(a) d a+(1-p)_{I^{*}} \int^{\infty} \exp (a) \phi(a) d a
$$

and,

$$
U=p_{-\infty} \int^{I^{*}-\beta} \exp (a) \phi(a) d a+(1-p)_{-\infty} \int^{I^{*}} \exp (a) \phi(a) d a .
$$

We assume that labor markets are competitive and that both types of labor are paid their marginal products. Namely,

$$
w^{E}=B E^{\rho-1}\left[B E^{\rho}+(1-B) U^{\rho}\right]^{\frac{1-\rho}{\rho}},
$$


and,

$$
w^{U}=(1-B) U^{\rho-1}\left[B E^{\rho}+(1-B) U^{\rho}\right]^{\frac{1-\rho}{\rho}},
$$

where $w^{E}$ and $w^{U}$ respectively denote the wage rates per efficiency units of labor supplied by educated and uneducated workers.

Taken together, equations (17)-(20) demonstrate how-ceteris paribus-higher degrees of screening biases lower the efficiency units of educated labor and raise the skill premium (by leading to an increase in the wage rate paid to educated labor, $w^{E}$, and an associated decline in that paid to uneducated labor, $\left.w^{U}\right)$. More formally, we can show that

$$
\begin{aligned}
\frac{\partial w^{E}}{\partial \beta}= & \frac{\partial w^{E}}{\partial E} \frac{\partial E}{\partial \beta}= \\
& (\rho-1) \frac{w^{E}}{E}\left\{1-\frac{1}{1+\frac{1-B}{B}\left(\frac{U}{E}\right)^{\rho}}\right\} \frac{(1-p) \phi\left(I^{*}\right)}{1+\frac{1-p}{p} \frac{\phi\left(I^{*}\right)}{\phi\left(I^{*}-\beta\right)}}\left\{\exp \left(I^{*}-\beta\right)-\exp \left(I^{*}\right)\right\} .
\end{aligned}
$$

and that

$$
\begin{aligned}
\frac{\partial w^{U}}{\partial \beta}= & \frac{\partial w^{U}}{\partial E} \frac{\partial E}{\partial \beta}= \\
& -(\rho-1) \frac{w^{U}}{E} \frac{1}{1+\frac{1-B}{B}\left(\frac{U}{E}\right)^{\rho}} \frac{(1-p) \phi\left(I^{*}\right)}{1+\frac{1-p}{p} \frac{\phi\left(I^{*}\right)}{\phi\left(I^{*}-\beta\right)}}\left\{\exp \left(I^{*}-\beta\right)-\exp \left(I^{*}\right)\right\}
\end{aligned}
$$

where $\frac{\partial w^{E}}{\partial \beta}>0$ and $\frac{\partial w^{U}}{\partial \beta}<0$ for $\rho<1$ and $\beta>0$.

When wages are determined endogenously, voters take into account not only how increases in the share of resources devoted to public education changes the odds of admission for their offspring but also how such increases alter the skill premium. Rewriting equation (8) to capture this change, we get 


$$
\begin{aligned}
\frac{\partial u_{L}}{\partial I^{*}}=-\frac{\lambda}{1-\tau^{*}} \frac{\partial \tau^{*}}{\partial I^{*}}- & (1-\lambda) \ln \left(\frac{w^{e}}{w^{u}}\right) \phi\left(I^{*}\right) \\
+ & \left(\frac{\Phi\left(I^{*}\right)}{w^{E}} \frac{\partial w^{E}}{\partial E}+\frac{1-\Phi\left(I^{*}\right)}{w^{U}} \frac{\partial w^{U}}{\partial E}\right) \frac{\partial E}{\partial I^{*}}=0
\end{aligned}
$$

where $\frac{\partial E}{\partial I^{*}}<0$ and

$$
\frac{\Phi\left(I^{*}\right)}{w^{E}} \frac{\partial w^{E}}{\partial E}+\frac{1-\Phi\left(I^{*}\right)}{w^{U}} \frac{\partial w^{U}}{\partial E}=\frac{\rho-1}{E}\left(\Phi\left(I^{*}\right)-\frac{1}{1+\frac{1-B}{B}\left(\frac{U}{E}\right)^{\rho}}\right) .
$$

The last term in (23) shows the effects of changing the share of resources devoted to public education on the skill premium. As we show in the appendix, this term is strictly positive for $\forall \rho<1$. That is, when the cost of education, $c$, is strictly positive or when parents put some positive weight on utility from their own consumption in period one, $\lambda>0$, the equilibrium share of resources devoted to public education supply is always less than that amount which would maximize second period output, $y_{2}$. Consequently, when wage rates are endogenously determined, screening biases have an additional positive impact on the share of resources devoted to public education finance. This directly follows from the fact that, with less efficient screening (i.e. higher $\beta$ ), aggregate units of educated labor input, $E$, declines and that of uneducated labor input, $U$, rises, thereby leading to an increase in the value of (24). In sum, endogenizing the wage rates not only rule out corner solutions in which no resources are devoted to public higher education, but it also demonstrates an additional potential effect on the political economy of education finance. That latter effect arises because-ceteris paribus-screening distortions inflate the skill premium by leading to more inefficient admissions.

\section{Related Literature}

Our model is closely related to a number of others in the existing literature. In two papers, Fernandez and Gali (1997) and Fernandez (1998) explore the role borrowing 
constraints play in the performance of exams versus markets as allocative mechanisms. In a model in which agents who differ in their initial wealth and ability are assigned to various investment opportunities or various quality schools, they show that exams dominate markets in terms of aggregate output. For sufficiently powerful (less biased) exam technologies, exams are superior to markets in terms of aggregate consumption as well. Glomm and Ravikumar (1992) compare the income distribution and growth implications of public versus private education. Their model is one in which all agents in the economy demand educational services to varying degrees and the quality of educational services depend on the total resources allocated to education. They find that private education, which will be chosen by higher income individuals, results in less subsequent mobility but higher growth rates. In contrast public education, which will be preferred by lower income groups, leads to greater social mobility at the expense of long-run economic growth. As a result, to the extent that the median voter is poorer than the mean income voter, public education is chosen in a more unequal society. Gradstein and Justman (1997) focus on why in a more democratic society that is unequal public education should be more likely to be chosen over private. They demonstrate that, because rational voters internalize all possible positive externalities of an education system, they do not necessarily choose one with more redistribution-public education in particular-over others that lead to higher long-run economic growth. Benabou (1996) reconciles the empirical observations that inequality is associated negatively with growth but not with redistribution. In his model, support for redistribution declines over at least some range because increases in inequality-in addition to putting more pressure for redistribution-also lead to an increase in the fraction of those who stand to loose from such policies.

There are a number of other papers related-somewhat less than those above-to what we present below. In particular, Fernandez and Rogerson (1996) present a model in which individuals stratify themselves into communities according to income, and demonstrate that policies that redistribute income to the relatively wealthy in poorer neighborhoods improve welfare. Stiglitz (1975) examines the role of screening in signalling private information on individual abilities and how it may affect the distribution of income. In a static model in which the amount of resources spent on public education makes screening 
more accurate, he demonstrates that the median voter will prefer to allocate more than the socially optimal, net output maximizing, share of resources on public education if individuals are informed about their abilities.

\section{Conclusion}

Distortions in screening for admission to schools are relevant for the political economy of public education finance because they influence voters' preferences. The model we present above highlights how such distortions in screening affect resources devoted to public education finance and their interplay with income inequality. It demonstrates that, while lower screening biases lead to higher allocative efficiency, they do not necessarily lead to more political support for public higher education, and thereby to higher aggregate human capital and output.

In particular, we find that screening biases affect the share of resources devoted to public education through three channels: First, they shift the relative position of influential voters' children who benefit from biases in the competition to qualify for admission to schools. When biases are relatively large, other voters benefit from this shift because their odds of entry to a public school at the margin rise. In contrast, when biases are rather moderate, they lose from such a shift because higher biases in that case means more competition from the children of influential parents. Second, when there are screening biases, more resources need to be devoted to public education supply as a higher fraction of individuals qualify for admission to schools. For fixed

wage rates, the exclusion effect of screening distortions are strongest when biases are moderate and less influential voters will choose to allocate a smaller fraction of resources to public education when biases are relatively small. When wage rates are endogenous and there exist complementarities between educated and uneducated labor in production, we show that screening biases need to be even smaller for biases to lead to fewer resources being devoted to public higher education supply. That is because biases, which lead to inefficiencies in higher education admissions, artificially inflate the skill premium.

Thus, the model above shows that while moderate to low degrees of screening bias lower the equilibrium share of resources devoted to public education, higher levels of bias 
may have positive effects on public education supply. A corollary is that higher inequality will lead to a lower share of resources being allocated to public higher education when biases are relatively moderate.

There are a number of important extensions of this framework which we plan to investigate in future research. For example, in the analysis above, we have abstracted from the effects of screening biases on the dynamic evolution of an economy. Nonetheless, given that these biases interact with income inequality to determine the share of resources devoted to the supply of public higher education, which in turn determine the fraction of educated workers in an economy, a closer examination of how economies evolve when there are biases could be fruitful. We may also use the above framework to address how the institution or abolition of affirmative action policies could potentially affect the support for higher public education and the subsequent dynamics of human capital accumulation, income inequality and economic growth. 


\section{Appendix}

8.1. When the proxy has measurement error:

We modify equation (4) to reflect family backgrounds biases as well as measurement errors.

$$
I^{i}= \begin{cases}a_{i}+\beta+\varepsilon_{i} & \text { with probability } p \\ a_{i}+\varepsilon_{i} & \text { with probability } 1-p\end{cases}
$$

where the error term, $\varepsilon_{i}$, is log-normally distributed, with $\varepsilon_{i} \sim N(0,1)$. Consequently, we also need to modify the offspring's expected income:

$$
E\left[\ln \left(c_{i, 2}\right)\right]=\ln \left(w^{u}\right)_{-\infty} \int^{\infty} \Phi\left(a_{i}^{*}\right) \phi(\varepsilon) d \varepsilon+\ln \left(w^{e}\right)_{-\infty} \int^{\infty}\left[1-\Phi\left(a_{i}^{*}\right)\right] \phi(\varepsilon) d \varepsilon,
$$

where $a_{i}^{*}=a_{p}^{*}=I^{*}-\beta-\varepsilon$ if the parent is influential and $a_{i}^{*}=a_{1-p}^{*}=I^{*}-\varepsilon$ if he is not.

Rewriting the first-order condition originally given by (6), we get

$$
\frac{\partial u_{L}}{\partial I^{*}}=-\frac{\lambda}{1-\tau^{*}} \frac{\partial \tau^{*}}{\partial I^{*}}-(1-\lambda) \ln \left(\frac{w^{e}}{w^{u}}\right)_{-\infty} \int^{\infty} \phi\left(I^{*}-\varepsilon\right) \phi(\varepsilon) d \varepsilon,
$$

where

$$
\frac{\partial \tau^{*}}{\partial I^{*}}=-\frac{c}{y}\left[p_{-\infty} \int^{\infty} \phi\left(I^{*}-\beta-\varepsilon\right) \phi(\varepsilon) d \varepsilon+(1-p)_{-\infty} \int^{\infty} \phi\left(I^{*}-\varepsilon\right) \phi(\varepsilon) d \varepsilon\right]
$$

Thus, equation (10) becomes

$$
\frac{\partial \tau^{*}}{\partial \beta}=\frac{p}{G_{\tau^{*}}} \frac{\lambda}{1-\tau^{*}} \frac{c}{y}\left[\begin{array}{c}
2_{-\infty} \int^{\infty}\left(I^{*}-\beta-\varepsilon\right) \phi\left(I^{*}-\beta-\varepsilon\right) \phi(\varepsilon) d \varepsilon \\
+ \\
\frac{-\infty \int^{\infty} \phi\left(I^{*}-\beta-\varepsilon\right) \phi(\varepsilon) d \varepsilon}{1-\tau^{*}} \frac{c}{y} \psi\left(I^{*}\right)
\end{array}\right]
$$


The interpretation of (A.5) is similar to that of (10): The first term in brackets represents how, at the threshold $I^{*}$, a given supply of educational services benefit or harm less influential voters. This effect arises because screening biases shift the relative position of influential parents' offspring in the $I_{i}$ map, and the exclusion effect of biases on the equilibrium tax rates can be positive or negative depending on how large biases are. The second term in brackets represents the effect on utility of a higher fraction of children born to influential parents qualifying for admission at a given threshold, $I^{*}$. The effect on equilibirum tax rates of more competition at a given threshold is always negative. Therefore, as in (10), $\frac{\partial \tau^{*}}{\partial \beta}$ can be positive when biases are relatively large.

8.2. Proving there exists one interior solution, $\tau^{*}>0$, to maximization problem:

Using equations (7) and (8) we can rewrite the first-order condition as follows:

$$
\frac{\lambda}{(1-\lambda)} \frac{c}{y} \frac{1}{\ln \left(\frac{w^{e}}{w^{u}}\right)} \frac{1}{1-\tau^{*}}=\frac{\phi\left(I^{*}\right)}{\left[p \phi\left(I^{*}-\beta\right)+(1-p) \phi\left(I^{*}\right)\right]}
$$

Denoting $\frac{\lambda}{(1-\lambda)} \frac{c}{y} \frac{1}{\ln \left(\frac{w^{e}}{w^{u}}\right)}$ by $\Omega$, and substituting in for the p.d.f of a normal, we get

$$
\frac{\Omega}{1-\tau^{*}}=\frac{1}{(1-p)+p \gamma \exp \left(2 \beta I^{*}\right)} ; \quad \gamma \equiv \exp \left(-\beta^{2}\right)
$$

Given that the l.h.s. of (A.2) is strictly convex and increasing in $\tau^{*}$, showing that the r.h.s. is decreasing in $I^{*}$ (which means it is increasing $\tau^{*}$ ) and that it has one inflection point will be sufficient to prove that the solution to the maximization problem specified in (1)-(5) will either have a unique interior solution, $\tau^{*}>0$, or a corner solution with $\tau^{*}=0$.

Let $f\left(I^{*}\right)=\frac{1}{(1-p)+p \gamma \exp \left(2 \beta I^{*}\right)}$. It is straightforward to show that

$$
\lim _{I^{*} \rightarrow-\infty} f\left(I^{*}\right)=\frac{1}{1-p} \quad \text { and } \quad \lim _{I^{*} \rightarrow+\infty} f\left(I^{*}\right)=0
$$


and that

$$
f^{\prime}\left(I^{*}\right)=-\frac{2 p \beta \gamma}{(1-p)^{2} \exp \left(-2 \beta I^{*}\right)+2 p(1-p) \gamma+p^{2} \gamma^{2} \exp \left(2 \beta I^{*}\right)}<0
$$

Moreover, (A.4) implies

$$
\lim _{I^{* \rightarrow|\infty|}}=0
$$

Using (A.4) we derive

$$
f^{\prime \prime}\left(I^{*}\right)=2 \beta f^{\prime}\left(I^{*}\right)\left\{1-\frac{2 p \gamma}{p \gamma+(1-p) \exp \left(-2 \beta I^{*}\right)}\right\} .
$$

Thus,

$$
\operatorname{sign}\left[f^{\prime \prime}\left(I^{*}\right)\right]=\operatorname{sign}\left\{\frac{2 p \gamma}{p \gamma+(1-p) \exp \left(-2 \beta I^{*}\right)}-1\right\}
$$

and,

$$
\begin{aligned}
& \operatorname{sign}\left[f^{\prime \prime}\left(I^{*}\right)\right]=- \text { as } \quad I^{*} \rightarrow-\infty \\
& \operatorname{sign}\left[f^{\prime \prime}\left(I^{*}\right)\right]=+ \text { as } \quad I^{*} \rightarrow+\infty
\end{aligned}
$$

Since, $\frac{2 p \gamma}{p \gamma+(1-p) \exp \left(-2 \beta I^{*}\right)}$ increases monotonically in $I^{*}$, sign $\left[f^{\prime \prime}\left(I^{*}\right)\right]=0$ only once, when $2 p \gamma=p \gamma+(1-p) \exp \left(-2 \beta I^{*}\right)$. Thus, $f\left(I^{*}\right)$ has a single inflection point $\tilde{I}=\frac{\beta^{2}+\ln \left(\frac{1-p}{p}\right)}{2 \beta}$. 
8.3. Proving that $\left(\Phi\left(I^{*}\right)-\frac{1}{1+\frac{1-B}{B}\left(\frac{U}{E}\right)^{\rho}}\right)$ is strictly positive when $\rho<0$ :

For heuristic purposes, consider the case in which distribution of abilities are uniform and all individuals have unit ability. Then, $\Phi\left(I^{*}\right)=U, U=1-E$, and the amounts of efficiency units of educated and uneducated labor that maximize second period aggregate output, $y_{2}$, are given by

$$
\left(\frac{U}{E}\right)=\left(\frac{B}{1+B}\right)^{\frac{1}{\rho-1}}
$$

It is then trivial to show that $\Phi\left(I^{*}\right)-\frac{1}{1+\frac{1-B}{B}\left(\frac{U}{E}\right)^{\rho}}=0$ when (A.10) is satisfied. Noting that, because $c, \lambda>0$, parents will chose to educate fewer indiviudals than that required to satisfy (A.10), completes the proof. 


\section{References}

Alesina, A. and D. Rodrik, 1994, "Distributive Politics and Economic Growth," Quarterly Journal of Economics, vol. 100, no. 4, 818-34.

Benabou, R., 1996, "Unequal Societies," NBER Working Paper No: 5583, May.

Conway, M., 1991, Political Participation in the United States, (U.S. Congressional Quarterly Press, Washington D.C.).

Edsall, T., 1984, The New Politics of Inequality, (W. W. Norton \& Company, New York).

Fernandez, R. and R. Rogerson, 1995, "On the Political Economy of Education Subsidies," Review of Economic Studies, 62, 249-62.

Fernandez, R. and R. Rogerson, 1996, "Income Distribution, Communities, and the Quality of Public Education," Quarterly Journal of Economics, 111(1), February, 13564.

Fernandez, R. and J. Gali, 1997, "To Each According to...? Markets, Tournaments, and the Matching Problem with Borrowing Constraints," NBER Working Paper No: 5930, February.

Fernandez, R., 1998, "Education and Borrowing Constraints: Tests vs. Prices," unpublished manuscript.

Galor, O. and J. Zeira, 1993, "Income Distribution and Macroeconomics," Review of Economic Studies, April, 38(3-4), 817-26.

Gradstein, M. and M. Justman, 1997, "Democratic Choice of an Education System: Implications for Growth and Income Distribution," Journal of Economic Growth, vol. 2, June, 169-83.

Glomm, G. and B. Ravikumar, 1992, "Public versus Private Investment in Human Capital: Endogenous Growth and Income Inequality," Journal of Political Economy, vol. 100, no. 4, 818-34.

Iyigun, M. F., forthcoming, "Public Education and Intergenerational Economic Mobility," International Economic Review. 
Peltzman, S., 1973, "The Effect of Government Subsidies-in-Kind on Private Expenditures: The Case of Higher Education," Journal of Political Economy, 81, 1-27.

Perotti, R., 1994, "Income Distribution and Investment," European Economic Review, 38, 827-35.

Perotti, R., 1996, "Income Distribution, Democracy and Growth: An Empirical Investigation," Journal of Economic Growth, vol. 1, no. 2, June, 149-87.

Psacharopoulos, G., 1986, Financing Education in Developing Countries, (World Bank: Washington D. C.).

Radner, R. and L. Miller, 1970, "Demand and Supply in U.S. Higher Education: A Progress Report," American Economic Review, 60, May, 326-34.

Stiglitz, J. E., 1974, "The Demand for Education in Public and Private School Systems," Journal of Public Economics, 3, November, 349-85.

Stiglitz, J. E., 1975, "The Theory of "Screening", Education, and the Distribution of Income," American Economic Review, 65(3), June, 283-300. 


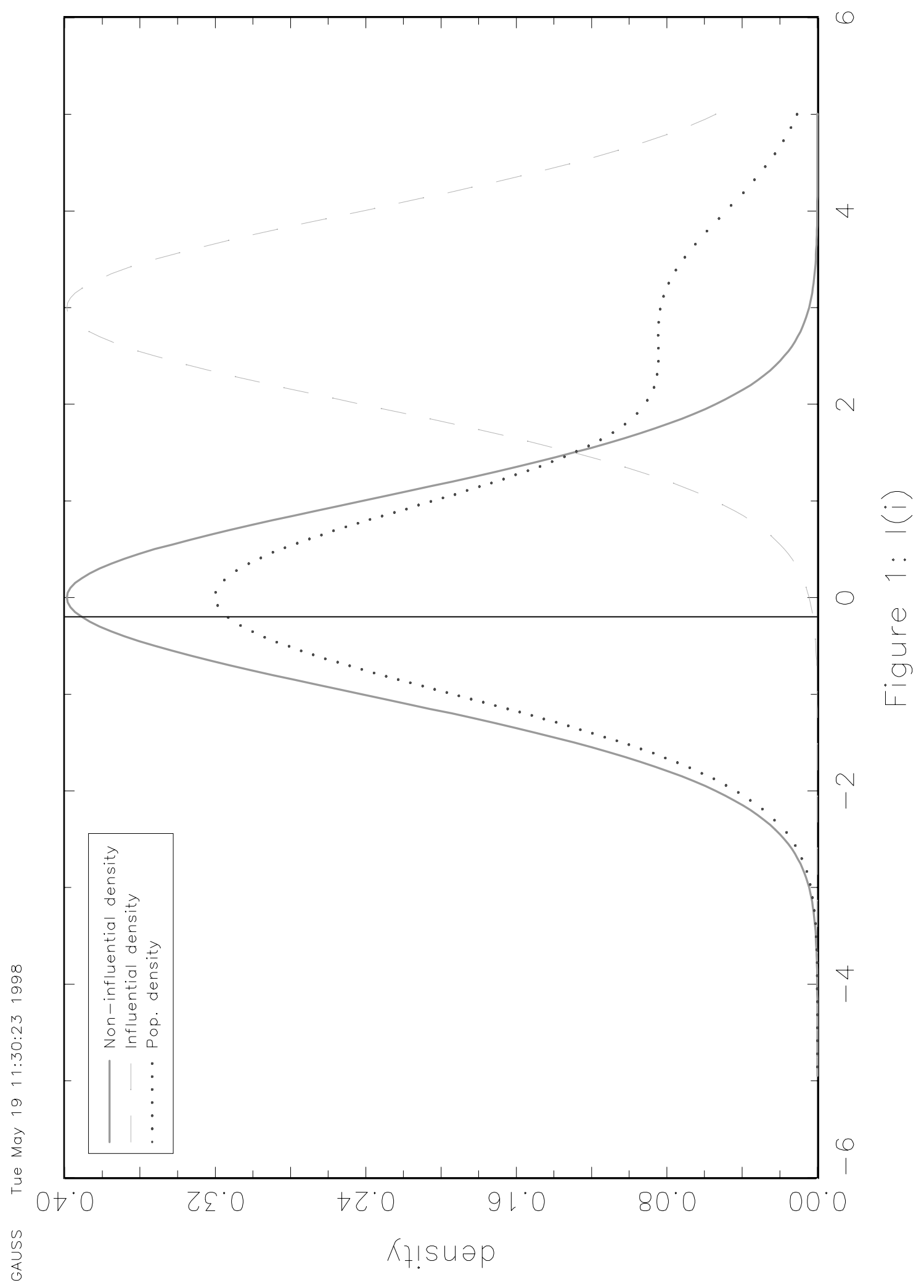




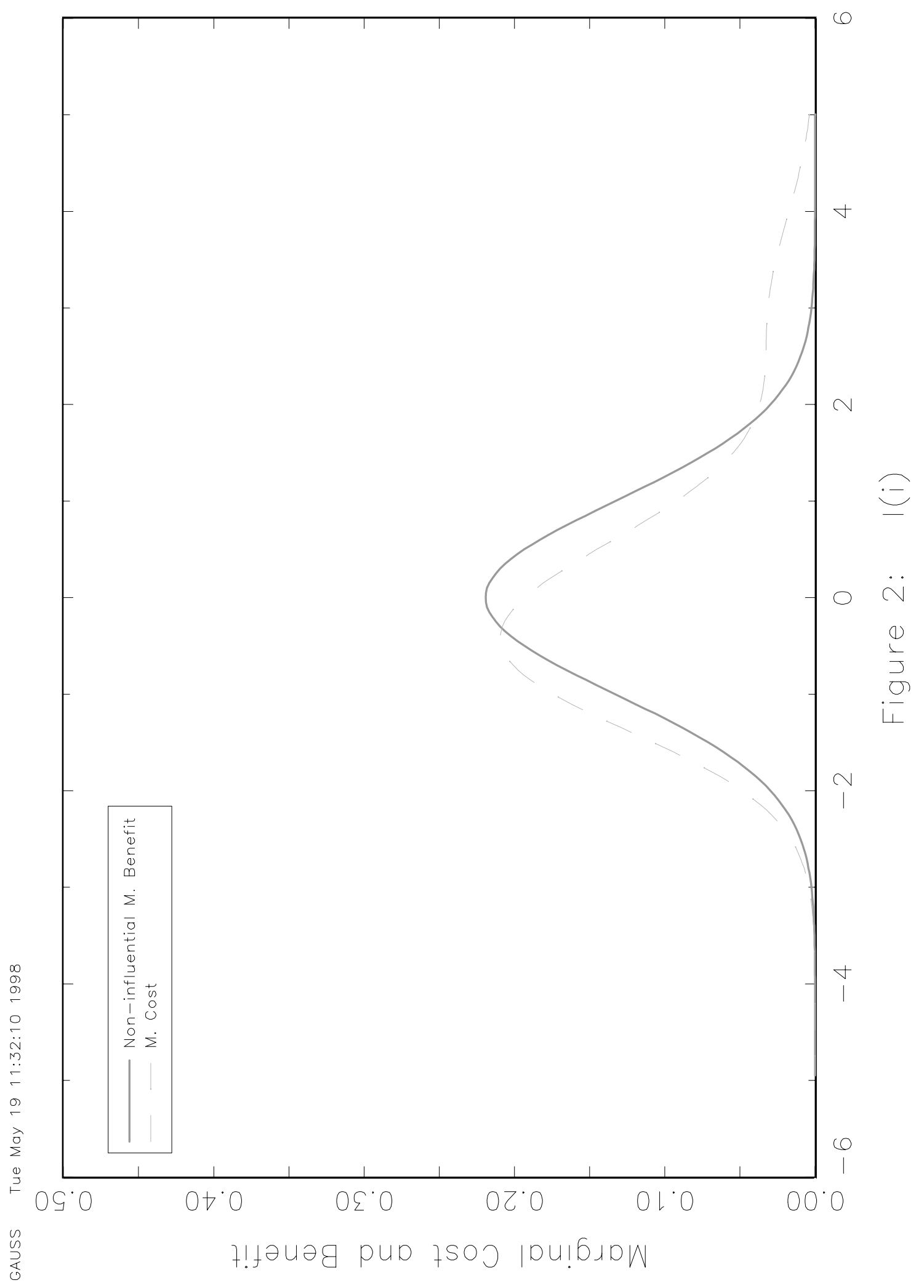




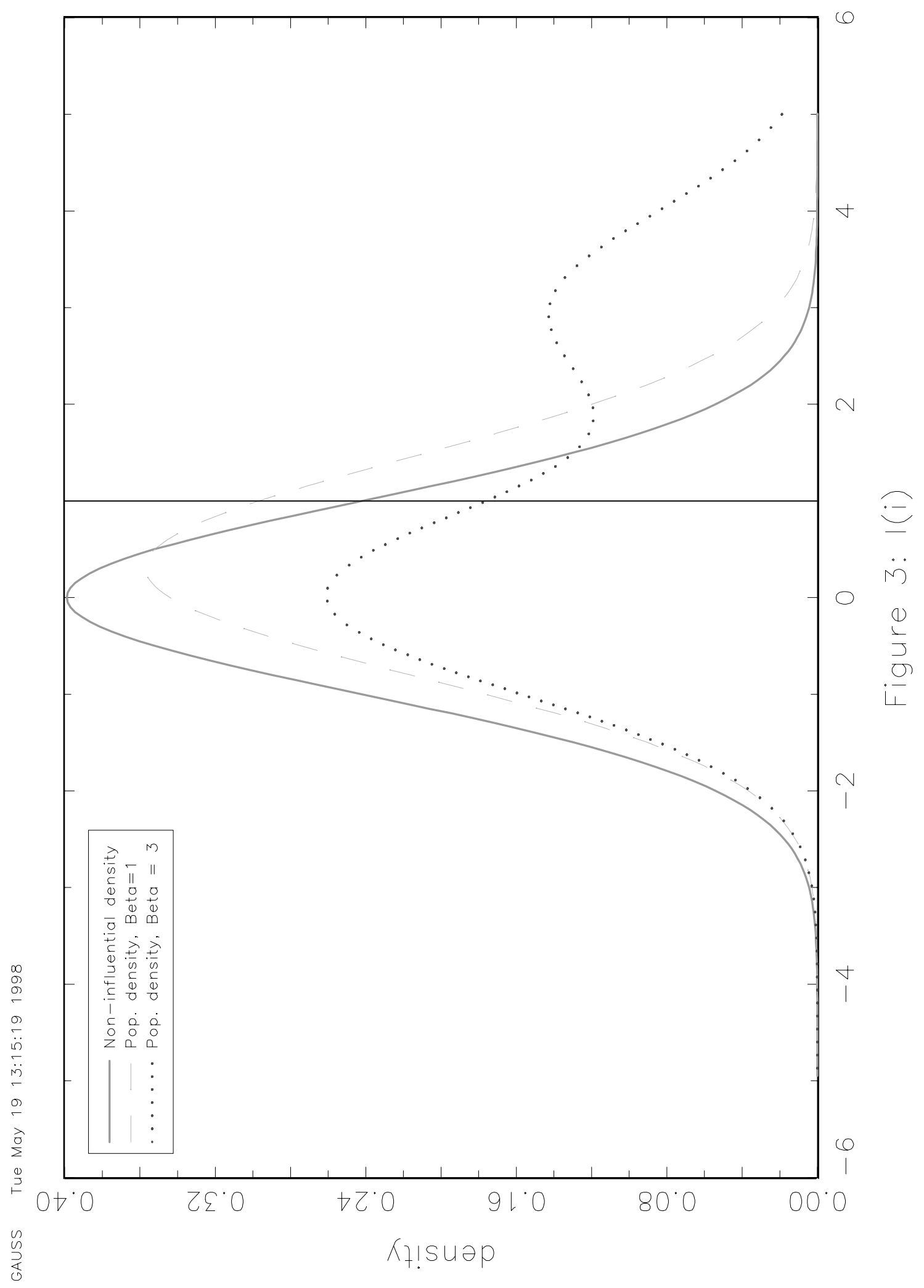




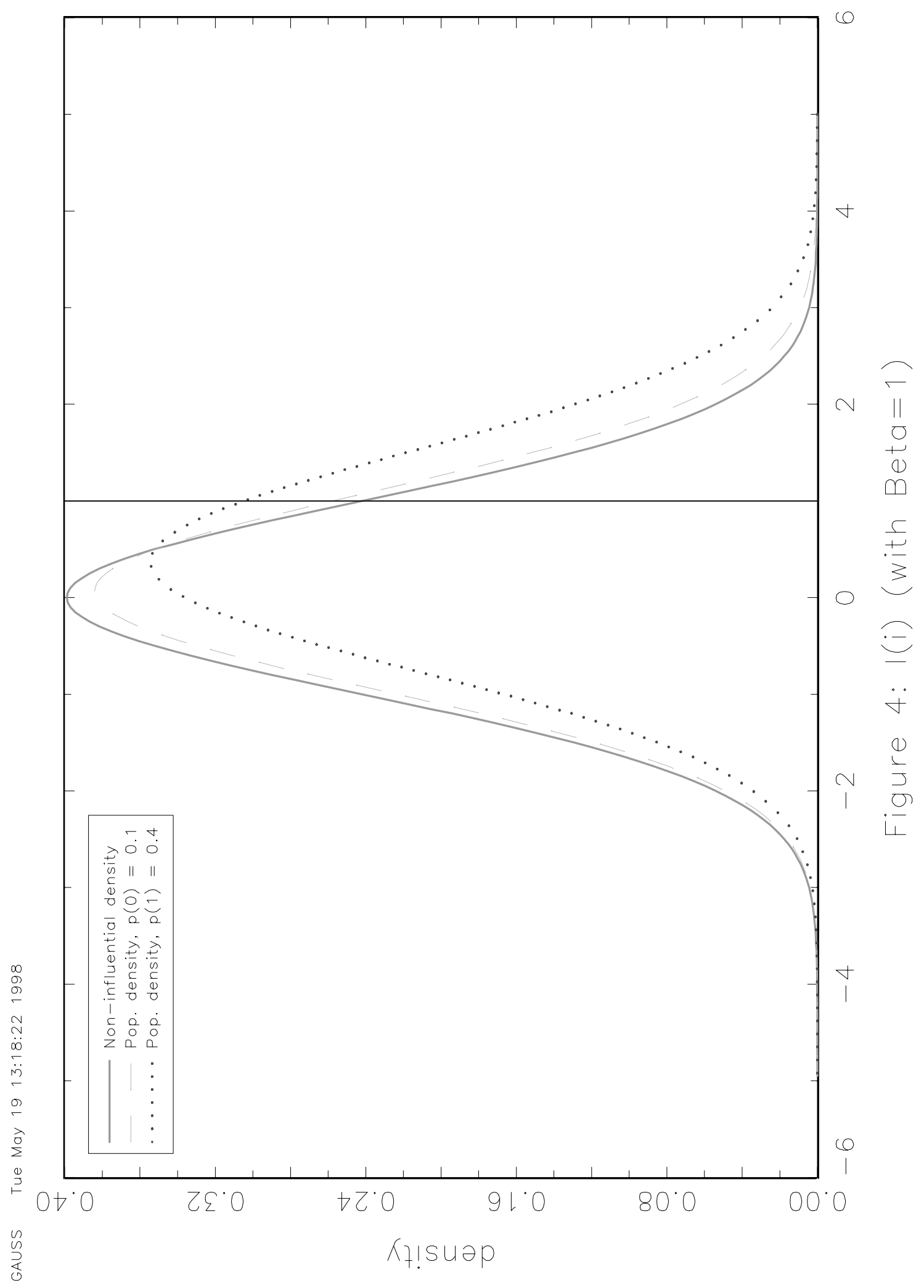




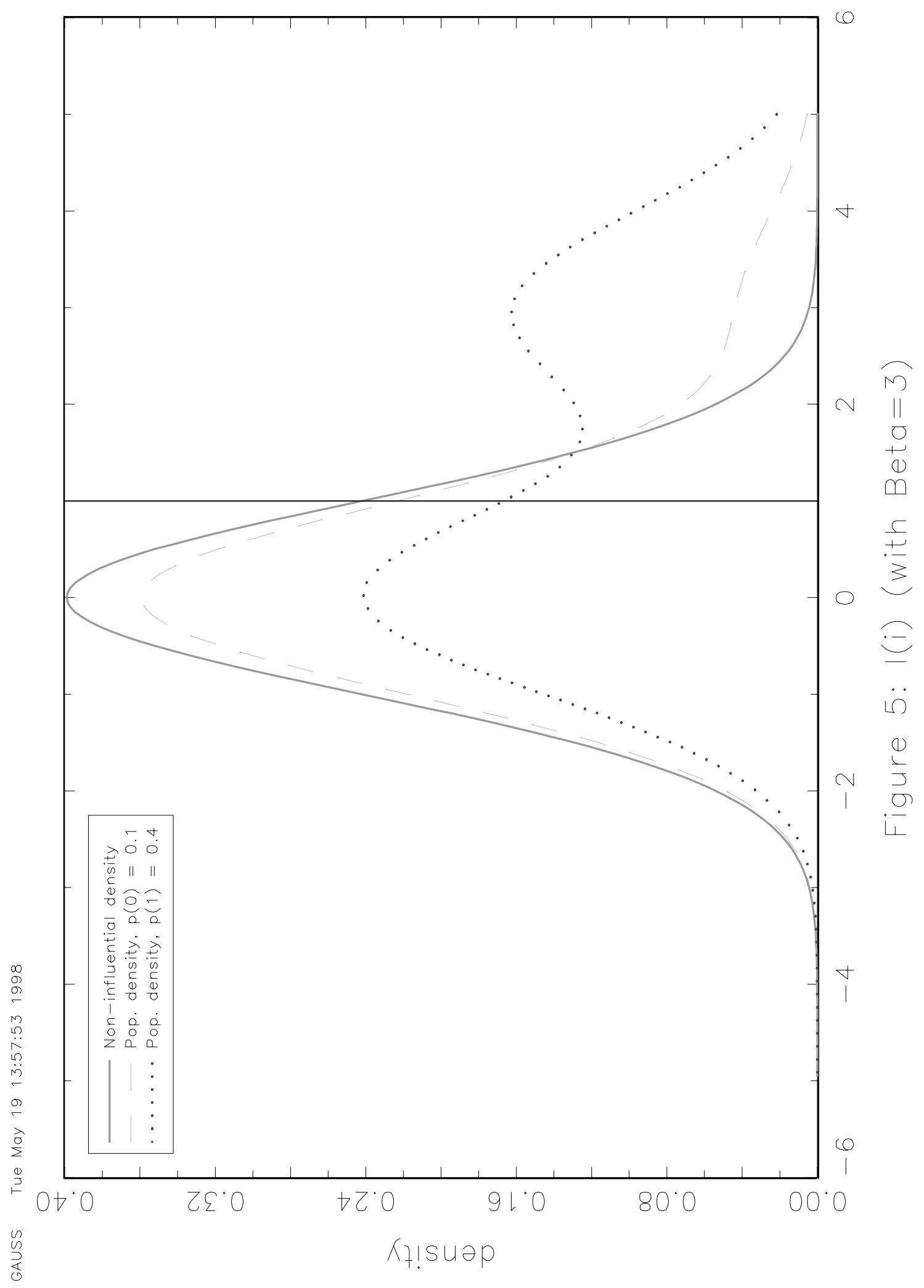

